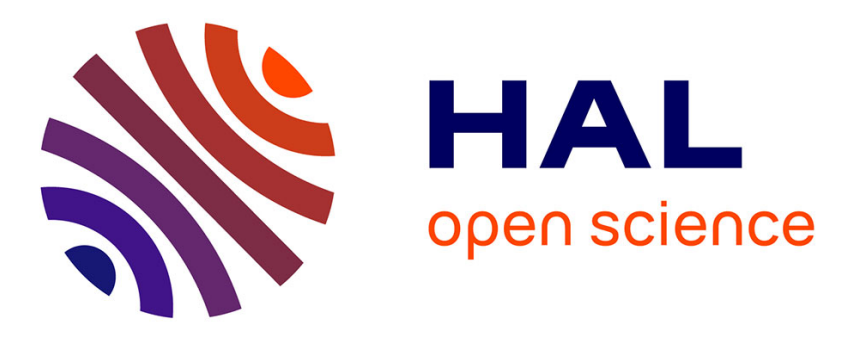

\title{
Synergies between theoretical approaches to mathematics education with technology: A case study through a cross-analysis methodology
}

\author{
Mirko Maracci, Claire Cazes, Fabrice Vandebrouck, Maria Alessandra
}

Mariotti, Maria Alessandra Mariotti

\section{To cite this version:}

Mirko Maracci, Claire Cazes, Fabrice Vandebrouck, Maria Alessandra Mariotti, Maria Alessandra Mariotti. Synergies between theoretical approaches to mathematics education with technology: A case study through a cross-analysis methodology. Educational Studies in Mathematics, 2013, 84 (3), pp.461-485. 10.1007/s10649-013-9495-1 . hal-02513063

\section{HAL Id: hal-02513063 \\ https://hal.science/hal-02513063}

Submitted on 23 Mar 2020

HAL is a multi-disciplinary open access archive for the deposit and dissemination of scientific research documents, whether they are published or not. The documents may come from teaching and research institutions in France or abroad, or from public or private research centers.
L'archive ouverte pluridisciplinaire HAL, est destinée au dépôt et à la diffusion de documents scientifiques de niveau recherche, publiés ou non, émanant des établissements d'enseignement et de recherche français ou étrangers, des laboratoires publics ou privés. 


\title{
Synergies between theoretical approaches to mathematics education with technology: a case study through a cross-analysis methodology
}

\author{
Mirko Maracci \\ Department of Mathematics, University of Pavia, Italy \\ Via Ferrata, 1- 27100 Pavia, Italy \\ Telephone number: +390382985659 \\ Fax number: +390382985602 \\ Email address: mirko.maracci@unipv.it \\ URL: http://www-dimat.unipv.it/ maracci \\ Claire Cazes
}

Laboratoire de Didactique André Revuz, Université Paris Diderot, France

75205 PARIS Cedex 13, France

Fabrice Vandebrouck

Laboratoire de Didactique André Revuz, Université Paris Diderot, France

75205 PARIS Cedex 13, France

Maria Alessandra Mariotti

Department of Mathematics and Computer Science, University of Siena, Italy

Pian dei Mantellini, 44 - 53100, Siena, Italy.

\begin{abstract}
Mathematics education as a research domain is characterized by a plurality of theoretical approaches. Acknowledging the existence of such diversity and the risks of an excessive theoretical fragmentation does not mean to search for a unifying theory but to urge the community to develop strategies for coping with this diversity. This article is meant to show the potential of a "cross-analysis" methodology for establishing connections between different theoretical approaches to mathematics education with technology. Within the frame of the ReMath European Project, two Teaching Experiments were realized, centred on the use of a same ICT tool Casyopée. Two distinct theoretical approaches shaped both the Teaching Experiments design and their enactments: the Theory of Didactical Situations and the Theory of Semiotic Mediation. The two Teaching Experiments have then been analysed from both theoretical points of view. In this article we will provide some examples drawn from this cross-analysis that show the synergy which can be established between the aforementioned theoretical approaches. Beyond contributing to a deeper understanding of the observed "didactical phenomena", that synergy allows establishing connections between the two approaches that lead to their reciprocal enrichment.
\end{abstract}


Keywords: Mathematics education with technology, Synergy between theoretical frameworks, Cross-experimentation, Instrumental approach, Theory of Didactical Situations, Theory of Semiotic Mediation.

\section{Introduction}

Current literature shows a great number of studies concerning different issues related to the use of ICT for teaching and learning mathematics. Hence the huge number of participants attending the $17^{\text {th }}$ ICMI study, Mathematics Education and Technology - Rethinking the Terrain (Hoyles \& Lagrange, 2010) was not surprising. This witnesses that Mathematics Education and Technology is an extremely lively international research field.

However, this research domain and the spreading of its results suffer from the diversity and fragmentation of existing theoretical frameworks within which the different studies are carried out (Artigue, 2008; Artigue, Cerulli, Haspekian, \& Maracci, 2009; Bottino, Artigue, \& Noss, 2009). An explicative hypothesis of this fragmentation is that these theoretical frameworks emerge from educational cultures of different countries and therefore they present differences that make them difficult to connect (Kynigos \& Psycharis, 2009). The existence of a plurality of theoretical approaches, often weakly connected amongst themselves, is not certainly specific to research in mathematics teaching and learning through technology. This issue has raised more and more the interest of the community of the mathematics education researchers, and led to the development of the notion of networking of theories as a research practice (Bikner-Ahsbahs, 2010; Prediger, Bikner-Ahsbahs, \& Arzarello, 2008). More recently, networking of theories itself has been conceptualized and framed according to different perspectives (Artigue, Bosch, \& Gascón, 2011; Kidron, Bikner-Ahsbahs, Monaghan, Radford, \& Sensevy, 2011; Mason, 2010; Monaghan 2010; and Radford, 2008).

In research practice, Prediger, Bikner-Ahsbahs and Arzarello (2008) recognized different networking strategies - understanding others and making one's own theory understandable, comparing and contrasting, coordinating and combining, synthesizing and integrating - according to the different aims pursued through the networking of theories.

This research study stems from the ReMath European Project, which involved seven teams from four different European countries (France, Greece, Italy and United Kingdom). The ReMath Project was meant to address the issue of the plurality of theoretical frameworks in mathematics education with technology, limiting the risk of theoretical fragmentation but without losing the richness which such a plurality brings. Empirical research was carried out with the aim both to enhance our understanding of meaning-making through representing mathematics with digital media and to develop an Integrated Theoretical Framework (Artigue, 2009). Hence the objectives of "understanding empirical phenomena" and "developing/elaborating/connecting existing theories" were pursued together. In 
particular, the development of the Integrated Theoretical Framework was based on a cyclical process which was framed by purposefully designed methodological tools and included the following activities:

a) The development of six ICT tools for representing mathematics concepts involving the domains of Algebra, Geometry and Applied Mathematics.

b) The development of thirteen context-sensitive Teaching Experiments (TEs) in a common format for the use of these tools.

c) The carrying out of empirical research involving cross-experimentation (Cerulli, Trgalova, Maracci, Psycharis, \& Georget, 2008) in realistic educational contexts, aiming at enhancing our understanding of meaning-making through representing with digital media (Mariotti \& Maracci, 2008).

The cross-experimentation consists of a set of TEs: for each ICT tool, at least two different TEs were designed and carried out in ordinary classes by two teams of two different countries - the team who designed the tool and another team with a different cultural and theoretical background.

This article relies on the cross-experimentation of Casyopée ${ }^{1}$ (Lagrange, 2010) one of the ICT tool developed within the ReMath Project - and on the related cross-analysis (described in section 4). Casyopée was developed by the French team Didirem and experimented by Didirem and the Italian Unisi team. The experiments and analyses are worked out through the lens of different theoretical frameworks: Didirem design and analysis are informed mainly by the Theory of Didactical Situations (TDS) (Brousseau, 1997) ${ }^{2}$ whereas Unisi relies on the Theory of Semiotic Mediation (TSM) (Bartolini Bussi \& Mariotti, 2008).

In this paper we mean to give an example of how a cross-analysis methodology helps establishing connections between different theoretical frameworks. We will focus on some aspects concerning the cross-analysis with the objective of discussing:

- How specific theoretical elements elaborated within the TSM and within the TDS can be connected to enrich the two theoretical perspectives.

\footnotetext{
${ }^{1}$ http://www.casyopee.eu

2 The Didirem team adapts recent developments concerning the construct of didactical contract (Hersant \& Perrin-Glorian, 2005), and combines the TDS with other theoretical approaches such as the Instrumental Approach (Artigue, 2002), the Anthropological Theory of Didactics (Chevallard, 1999) and the theory of semiotic registers (Duval, 1995). A discussion about the compatibility of all these theoretical constructs is beyond the scope of this article. Here compatibility has to be considered at the operational level of research practice. In this respect we remark that a number of French studies resorts a combination of the above theoretical constructs, used for different purposes at different grain sizes.
} 
- How analytical tools coming from the TSM and the TDS can be connected together in order to provide rich and deep insight of what happens in the classroom when an ICT tool is used.

We summarize all that saying that a synergy can be established between the two theoretical perspectives. The term synergy here is used after its common sense to signify the "the interaction of two or more agents or forces so that their combined effect is greater than the sum of their individual effects"3.

Section 2 provides a very short description of the ICT tool Casyopée and a comparison of the way of using it in each TE. The study of the relationship between theory and TE design and enactment was one of the interests of the ReMath Project. Nevertheless, since such relationship is not the focus here, in the description of the TEs we will limit the theoretical references, in order not to overload the reading. Section 3 is a presentation of the theoretical frameworks informing the analyses of the two TEs. Section 4 describes the cross-analysis methodology and reports on the results of the cross-analysis of two pieces of data of the two TEs. Sections 5 and 6 are devoted to the synthesis and the discussion of the results, and to some conclusive thoughts.

\section{Casyopée and its use in the two TEs}

This section is meant to concisely describe the design of the TEs, their enactment in the classrooms, and the Casyopée features used in the TEs, with the aim of providing the information needed for the reader to follow the a-posteriori analysis reported in section 4. We make use of the construct of Didactical Functionality (Cerulli, Pedemonte, \& Robotti, 2006) to frame the comparative description of the two TEs and the modalities of use of Casyopée. By Didactical Functionality of an ICT tool one means the system constituted by three interrelated poles: a set of features of the tool, a set of educational goals, and the modalities of employing the specified features of the tool for achieving the envisaged educational goals. Clearly, different theoretical perspectives can lead to design different Didactical Functionalities for a given tool.

\subsection{Tool Features}

Globally speaking, Casyopée integrates features of an Algebra Environment and of a Dynamic Geometry Environment (DG) and supports the algebraic modelling of geometrical situations through a purposefully designed environment: the socalled Geometric Calculation Environment.

Features of the Algebra Environment. This environment provides features for defining functions in one variable through an algebraic expression, displaying and exploring the graph of a function, manipulating algebraic expressions, calculating

\footnotetext{
${ }^{3}$ The Free Dictionary by Farlex, http://www.thefreedictionary.com.
} 
the derivative and the anti-derivative of a function, and so on. The user can also create parameters, specify their range of variation, assign to parameters specific numerical values, and change these values through the use of sliders. If a function depends on parameters, its graph depends on the specific values assigned to the parameters, and changes accordingly.

Features of the Dynamic Geometry Environment. This environment includes several commands usual to any DG environment. In particular, there is the possibility of creating points with different behaviours with respect to the dragging and movement, namely: fixed points, free points, constrained points, and points with parametric coordinates.

Features of the Geometric Calculation Environment. This environment is meant to support the algebraic modelling of a given geometrical situation; it constitutes the distinguishing feature of Casyopée. Three steps are needed to construct a modelling function: (a) Defining the so-called "geometrical calculation" one is interested in: it is the intended output of the function. (b) Selecting a "variable", the intended input of the function. Not all the variables are admissible. (c) Creating a function between the selected variable and the geometric calculation chosen. If such a function can be defined, then Casyopée computes a corresponding algebraic expression and exports the function in the Algebra environment.

\subsection{Educational Goals}

Both TEs share a common general educational focus on the mathematical notions of function ${ }^{4}$ (in particular, conceived as co-variation), variables (distinguishing between independent and dependent ones) and parameters, and a common focus on the modelling process. But the educational goals are different.

The Didirem TE aims to help students construct or enrich their knowledge concerning functions. In particular, knowledge concerning the treatment of functions in different settings and through different registers is assumed as a specific educational aim. The last part of the TE is meant to approach functions as means to algebraically model the co-variation of geometrical objects in a geometric context. In addition, the TE aims to develop students' operational knowledge concerning the use of Casyopée, involving both knowledge of the artefact and mathematical knowledge.

The Unisi TE aimed at fostering the evolution of students' personal signs towards (a) the mathematical signs of function as co-variation, and (b) the mathematical signs related to the algebraic modelling of geometrical situations. Though students are expected to have already received some formal instruction on the notions of

\footnotetext{
${ }^{4}$ Though the TEs concern the teaching and learning of functions, the focus of the article is not on this specific notion, but on the use of artefacts for fostering mathematics teaching and learning.
} 
function, a common experience of teachers and researchers is that meanings related to those notions are rarely elaborated in depth. The algebraic modelling of geometrical situations is addressed from the beginning of the TE.

\subsection{Modalities of Employment}

Each TE was implemented in ordinary classes. The modalities of employment of Casyopée are very different from one TE to the other and this is consistent with the different educational goals describe above. Here is a synthesis of the main aspects of the TEs; more details can be found in Maracci, Cazes, Vandebrouk and Mariotti (2009).

Consistently with the TDS (section 3.1) the Didirem TE alternates a-didactical situations, during which the students are expected to construct the knowledge at stake through interacting with a purposefully designed milieu, and institutionalization phases, in which the teacher and the students explicitly formulate, validate and de-contextualize the knowledge developed in a coconstruction process. The different environments of Casyopée (the algebraic, the geometric and the geometric calculation one) are introduced and worked on gradually. The TE was carried out in a $10^{\text {th }}$ grade class and was spread out over 3 months over 6 sessions (10 hours).

The whole TE of the Unisi team is informed by the TSM (section 3.2) and is structured in iterative didactical cycles entailing: (a) students' pair or small group activity with Casyopée for accomplishing a task, (b) students' personal rethinking of the class activity (through the explicit request of producing individual reports on that activity) and (c) classroom discussion orchestrated by the teacher. The TE was carried out in a $12^{\text {th }}$ grade class and spread out over 7 sessions (11 hours).

\section{Theoretical frameworks and analytical tools}

This section provides a concise presentation of the TDS and the TSM with a specific focus on the theoretical constructs used as analytical tools in the $a$ posteriori analysis of the TEs.

\subsection{The Theory of Didactic Situations}

At the core of the TDS there are the notions of a-didactical situation and of didactical contract (Brousseau, 1997; Perrin-Glorian \& Hersant, 2003; Hersant \& Perrin-Glorian, 2005). The former is the main source of inspiration for the design of teaching sequences, while the latter plays a crucial role mainly in the $a$ posteriori analysis.

Assuming a constructivist perspective, the TDS models the student as an epistemic subject who acts on an antagonist milieu according to her/his repertoire of knowledge. Brousseau (1997) defines the milieu as anything with which the student interacts to solve the task. It includes material and symbolic elements. The 
milieu reacts to the subject's actions through different types of feedback which are interpreted by the subject with respect to her/his knowledge. Thus, according to the TDS, crucial importance is assigned to the design of tasks having a so called a-didactical potential in some well-designed milieu. Such a-didactical situations allow students to construct the knowledge at stake as an optimal answer to the tasks involved in the situation, while the teacher has to be very cautious in her/his possible interactions with the students in order not to modify the designed tasks and make them easier (smooth their difficulties). In the following, the teacher acts at a didactical level and institutionalizes the knowledge emerged from students' solutions of the tasks; in this process such a knowledge is validated and decontextualized from the original situation. So, learning occurs in interplay through adaptations to the a-didactical situation and acculturation, mainly managed by the teacher.

The didactical contract is defined, after Brousseau (1997), as the educational system of expectations, explicit and implicit, linking the various actors in a didactical situation. The didactical contract shapes their relationships with respect to the problem solving and the mathematical knowledge at stake. More in detail, it is possible to identify different levels of the didactical contract, corresponding to different time scales and didactical aims (Hersant \& Perrin-Glorian, 2005). The notion of didactical contract is an effective tool for the a-posteriori analysis of a teacher's interventions and it allows accounting for the didactical regulations performed by the teacher in managing the class with respect to her/his didactical goals (ibidem).

\section{Tools for the analysis according to a TDS perspective}

Within the TDS frame, the analysis of the data coming from each TE focuses on the description of the task, the milieu and the didactical contract established between the students and the teacher.

a) The analysis of the tasks involved is carried out through two points:

(i) The status of the knowledge involved in the tasks. It can be new knowledge, knowledge in development or old knowledge. It can be mathematical knowledge or instrumental knowledge combining mathematics and knowledge about Casyopée.

(ii) The complexity of the tasks. Duval's theory of registers of representation (Duval, 1995) is introduced to categorize the complexity of the tasks given to students with their potential for mathematical learning. According to Duval's theory, the request of conversions between semiotic registers is assumed as a factor affecting the complexity of a task but also as a key factor fostering learning. However, other factors affecting the complexity of a task are the need of establishing connections between different pieces of knowledge, or the need of introducing not-indicated knowledge (Robert, 1998). Moreover, taking an instrumental approach, the 
complexity of the task to be accomplished with an artefact is also determined by the level of instrumentation required. ..

b) The milieu. We try to clarify its characteristics for a given problem. The possibilities for action on the milieu and the feedback it offers shape the knowledge which can be learned by the students.

c) The didactical contract. In particular, we mostly exploit the notion of distribution of responsibility and investigated how responsibility was distributed between teacher and students during the activities.

The development of students' knowledge towards the target institutional knowledge can be fostered through situations in which some new knowledge is involved in tasks with a reasonable level of complexity and when the responsibility of the tasks in the activity is well balanced between students and teacher. In any case, a phase of institutionalisation is needed to ratify the developed knowledge.

\subsection{The Theory of Semiotic Mediation}

In relation to the introduction of new technologies in school practice, the term mediation has been commonly employed to refer to the potentiality that a specific artefact has with respect to fostering learning processes, mostly alluding to its use for the accomplishment of tasks (Borba \& Villarreal, 2005; Meira, 1995; Noss \& Hoyles, 1996; Radford, 2003).

Drawing on a Vygotskyan perspective (Vygotsky, 1978), the TSM (Bartolini Bussi \& Mariotti, 2008) addresses the epistemological issue concerning the relationship between the accomplishment of a task through the use of an artefact and learning. It combines a semiotic and an educational perspective and elaborates on the notion of mediation (Hasan, 2002) considering the crucial role of human mediation (Kozulin, 2003, p.19) in the teaching-learning process through an artefact. Taking a semiotic perspective means to interpret the teaching-learning process recognizing the central role of signs $^{5}$ in the construction of knowledge, and focusing on the link that it is possible to establish between artefacts and mathematical knowledge. Specifically, taking a semiotic perspective means to focus on the processes of production and transformation of signs.

In synthesis, in a mathematics class context, when using an artefact for accomplishing a mathematical task, students can be led to produce personal signs which can be put in relationship with mathematical signs. However, the construction of such a relationship cannot be a spontaneous process for students. On the contrary it should be assumed as an explicit educational aim by the

\footnotetext{
${ }^{5}$ We assume an indissoluble relationship between signified and signifier. In the wake of other researchers (Radford, 2003; Arzarello, 2006) we developed the idea of meaning that originates in the intricate interplay of signs (Bartolini Bussi \& Mariotti, 2008).
} 
teacher, who can intentionally orient her/his own action towards promoting the evolution of signs expressing the relationship between the artefact and the tasks into signs expressing the relationship between the artefact and the knowledge at stake.

\section{Tools for the analysis according to a TSM perspective}

The analysis of the teaching-learning process is therefore centred on the analysis of semiotic processes occurring in the classroom, and in particular on the analysis of the interactions (mainly, verbal interactions) among the students and between them and the teacher. A TSM analysis is meant to investigate different interrelated aspects:

a) The possible unfolding of the hypothesized semiotic potential of the artefact in relation to the designed tasks, and in relation to the target mathematical meanings. The unfolding of the semiotic potential appears in the production and use (by students) of artefact-signs in ways which are pertinent to the tasks accomplished with the artefact, consistent with the artefact functionalities and consistent with mathematical potentialities of the artefact-signs themselves.

b) The possible evolution of students' personal signs towards the desired mathematical signs and the possible development of a texture of different meanings related to the target mathematical meanings, that (the texture) contributes to enrich already formed personal meanings. The evolution of students' personal signs towards the desired mathematical signs can be revealed through identifying expressions (produced by students) in which specific terms (function, variable...) are used to report on the tasks accomplished through the artefact. That witnesses how already formed personal meanings are related to or re-elaborated in light of the actual use of the artefact (including the specific kind of tasks accomplished through it), thus testifying a progressive enrichment of such meanings towards the formation of the desired mathematical meanings. In particular, one should identify the generation of semiotic chains (successive occurrences of related signs, Bartolini \& Mariotti, 2008, p. 755) showing how connections are established between artefact-signs and mathematical signs.

c) The possible exploitation by the teacher of the unfolded semiotic potential for fostering the evolution of students' signs. The analysis of the teacher's exploitation of the semiotic potential of an artefact requires the study of the strategies enacted by the teacher to facilitate such evolution. In this respect, attention is paid to the teacher's specific semiotic actions such as: the request to go back to the task, the request to focalize on specific aspects of the activity, the request to provide a synthesis, and the production of a synthesis by the teacher her/himself (Mariotti, 2009; Mariotti \& Maracci, 2010). In addition, it is important to investigate whether and how the teacher fuels the class discussion by contributing to the generation of semiotic chains in which connections between artefact-signs and mathematical signs are established. 


\section{Cross-Analysis}

According to the general plan of the ReMath Project, the Didirem team designed and developed a TE based on Casyopée, and so did the Unisi team. At first, each team gathered and analysed data from their own TE. Later on, within the Project, it was decided to carry out a cross-analysis of a selection of the data collected. That is, a selection of data coming from the Didirem TE was also analysed by the Unisi team according to its own theoretical perspective, and, conversely, a selection of data coming from the Unisi TE was also analysed by the Didirem team according to its own theoretical perspective. Then the analyses were compared, in a dialogue process between the two theoretical perspectives, seeking for possible complementarities, similarities, or even conflicts, with the aim of establishing a connection between them. The cross-analysis should not be thought of as a definite well-established methodology, but rather as a process which developed and was refined in use for the duration of the Project.

This process raised a crucial issue. In a TE, theories drive not only the design and implementation but also the collection of data: a priori no one could guarantee that a theory-driven selection of data could be analysed from a different theoretical perspective. In fact, the selection of the data for the cross-analysis was not a trivial enterprise. The pieces of data selected and presented in this paper concern two moments of the TEs, that are relevant from both a TDS and a TSM perspective: the students' use of an artefact for accomplishing a mathematical task and the development, through the teacher's intervention, of an explicit link between such use and the relevant mathematical knowledge.

The cross-analysis is carried out on: (a) some excerpts from the transcript of a laboratory session, in which two students used Casyopée for solving a task, and which is characterized by the interaction both between the students and between them and the teacher (drawn from the Didirem TE, section 4.1); and (b) some excerpts from the transcript of a collective discussion following laboratory sessions (drawn from the Unisi TE, section 4.2).

The cross-analysis will be presented alternating the contributions of TDS and TSM in a kind of dialogue between the voices of the two theoretical perspectives.

\subsection{Cross-analysis of a Didirem TE lab session activity}

The piece of data selected is drawn from an excerpt of a laboratory lesson devoted to an activity on quadratic functions. The notion of quadratic function was introduced by the teacher in the two previous lessons so the knowledge at stake is still in development.

\section{Global description of the problem}

The graph of a function is displayed in the Casyopée graphical frame. It is the graph of the function defined through the hidden 
expression

$t(x)=2 x^{2}-4 x-6$

Students are asked to insert into Casyopée three functions defined through parametric expressions:

$$
f(x)=a(x-d)^{2}+e ; g(x)=a\left[(x-k)^{2}+m\right] ; h(x)=a(x-u)(x-v) .
$$

Then, for each function they are asked to use Casyopée to find those values of the parameters ${ }^{6}$ which make the corresponding graph coincide with the graph of the given hidden function $(a=2, d=k=1$, $e=-8, \quad m=-4, \quad u=3$ and $v=-1)$ and to compute the algebraic development of the expressions obtained (task 1, in the following). In addition they are asked to explain their method (task 2) and to specify their interpretation concerning the role of parameters with respect to the variation and displacement of the graphs of the functions (task 3).

Consistently with a TDS perspective, the analysis of the students' activity has to entail the a-priori analysis of the tasks proposed to them, and the specification of the milieu/milieux and of the didactical contract established in the classroom.

Analysis of the tasks

The tasks given to students are designed to make students strengthen the knowledge in development (the meaning of variable, the distinction between variable and parameter, the meaning of function of one variable within several registers of semiotic representation) and develop new knowledge (specifically about quadratic functions and generally about the fact that a same function may have several algebraic expressions). In order to solve the tasks students have to connect the meaning of the parameters, within the algebraic expressions defining the given functions, with the variations or displacements of the graphs of these functions observed in the graphical window. The tasks involve two registers of representations for functions (Duval, 1995): the algebraic and the graphical ones. Conversions between the two registers are needed to solve the tasks.

\section{Milieu, milieux}

Adapting the terminology introduced by Margolinas (1995) and used by Hersant and Perrin-Glorian (2005), we are led to distinguish between the material milieu, which is constituted by the material objects available to the students in order to engage the task, and the objective milieu, which is constituted by the knowledge needed for the students to interact effectively with the situation at stake. In particular the objective milieu entails the mathematical knowledge at stake. The considered laboratory session took place at the beginning of the TE, and the material milieu is constituted by the Casyopée Algebra Environment.

\footnotetext{
${ }^{6}$ In this task the parameters can only take on integer values.
} 


\section{Contract}

In this session, students work in pairs, but each student has a computer. They collaborate to solve the given task, each of them working with Casyopée on her/his computer. According to the specific macro didactical contract (Hersant \& Perrin-Glorian, 2005) established within the class, the responsibility of the whole activity is mainly left to the students. Students are expected to progress in the solution of the tasks as autonomously from the teacher as possible. The teacher should intervene only to help students overcome any possible impasse, specifically those related to technical problems.

In the following we present the analysis of some excerpts of the dialogue between two students (Jus and Luc) and between them and the teacher.

\section{Excerpt 1: functioning of the a-didactical situation - unfolding of the semiotic potential}

In the previous part of the lab session, Jus and Luc worked on the function $f$, found the correct values of the parameters of $f(a, d, e)$ - i.e. the values of the parameters which make the graph of the function $f$ coincide with the graph displayed in Casyopée - and developed correctly the algebraic expression (task 1). This excerpt shows the two students engaged in finding the values of the parameters for the function $g$ (defined through $g(x)=a\left[(x-k)^{2}+m\right]$ ). At this stage, students could choose between two procedures: they could work within the algebraic register, computing the algebraic expression of $g$ and comparing it with the algebraic expression of $f$, or they could find the values of the parameters by graphical adjustments, according to the dialectics of action and retro-action originated by the specific feedback provided by the objective milieu.

27. Jus: [varying the values of the parameters and looking at the effect on the motion of the graph in the graphical window] Well, we just have to go down (French term: descendre)

28. Luc: Well, again 2, -8 ; here we are $\ldots{ }^{7}$

29. Jus: No, just a minute, what?

30. Luc: Well, it is not possible to go slower [When the value of $m$ decreases by 1 unit, the graph moves down along the $y$-axis by 2 units]

31. Jus: Look, I have it there; do you have it in the same position?

32. Luc: Maybe

33. Jus: We have to decrease $k$ (French term: descendre)

72 and -8 are the correct values of two parameters ( $a$ and $e$ ) which appear in the expression of $f$.

The parameter $a$ still appears in the expression of $g$, and its correct value is still 2, whereas the parameter $e$ is not a parameter for $g$. Another parameter for $g$ is $m$ (quoted later in the discourse), and its correct value is -4 . 
34. Luc: No, not exactly, watch, I have it there ...

35. Jus: No, I do not have the same thing, maybe because our parameters are not the same

36. Luc: Well $a$ is 2 and for $e$ you had -8

37. Jus: Well, first of all there is not $e$ so it is obvious that it doesn't work, so it is $m$ that $\mathrm{I}$ have to change.

38. Luc: So there is not $e$

39. Jus: No, as for $m$, we have to put $8, . .$, no it is not $8, m$ is... yes, $m$ is 4

40. Luc: But as for $e$ you had -8 , do you?

41. Jus: Yes, but $e$ is not interesting, it is not among the parameters

42. Luc: Ah, yes, so, $m$ is $-4, a$ is 2 and $k$ is 1

[Luc and Jus assign the found values to the parameters and develop the algebraic expression of $g$.]

43. Luc: It is...it is the same quadratic expression, so it is the same

44. Jus: That is $x^{2}-2 x+1$, then we multiply by 2 and we add -4 ; so one gets $2 x^{2}-4 x+2+(-4)$

45. Luc: So, one gets $2 x^{2}-4 x-6$ and well... it is the same ${ }^{8}$

46. Jus: It may be coherent

47. Luc: Of course, it is right

48. Jus: It is obvious any way

49. Luc: Yes, my result is the same too

50. Jus: In my opinion there is no mistake because the graphs are similar.

Up to item 42, Luc does not identify the pertinent parameters from the algebraic expression of the function $g$. Initially, he seems to expect to solve the task just giving the same values to the parameters as in the previous part of the session (involving the function $f$ ) (36.), even if the two functions $f$ and $g$ have different expressions that involve different parameters.

TDS. The students use the graphical procedure to achieve the task. This is consistent with the local contract which favors this procedure. However, Luc engages the task correctly only after interacting with Jus (42.). In fact, Jus and Luc realize that something is wrong through comparing the different positions of their respective graphs in the Cartesian plane (34. and 35.). So, it is the interplay

\footnotetext{
${ }^{8}$ The same expression was obtained for the function $f$.
} 
between interactions with the milieu and social interactions ${ }^{9}$ that leads the students to solve the task. This is allowed by the structure of the material milieu which is very rich. On the one hand each student works on her/his computer and hence receives feedback to her/his actions directly from Casyopée. On the other hand they interact with each other and receive another kind of feedback through comparing what appears on the two screens. This leads Jus and Luc to direct their attention to the parameters manipulated (35.) and to the expression of $g$, and then allows them to identify the pertinent parameters (37. and 41.) and find their correct values.

TSM. A semiotic analysis reveals traces of the unfolding of the semiotic potential of Casyopée with respect to the given task. Artefact-signs are produced by students and used in ways consistent both with the artefact functionalities and with the mathematical potentialities of the artefact-signs themselves, such as: the term "descendre" which can be referred both to the position of the graph - "go down" (27.) - and to the value of the parameter - "decrease" (33.), and the term "parameters", which can be referred both to the mathematical notion, and to the labels present in the algebraic expression, and to the Casyopée-objects with all their possible manipulation (we note that at the very beginning students seem to conceive parameters like software commands for manipulating graphs).

The students' interventions open the possibilities of starting an explicit reflection from the interpretation of the actions on the parameters as graph transformations, to the study of the relationship between the parameters values and the graph of the function, and hence between the algebraic expression of a function and its graph.

TDS. In the last part of the dialogue (43.-50.), the students obtain a further validation of their solution by comparing the algebraic expressions of the two functions $f$ and $g$ (while they did not consider the algebraic expressions for the selection of the parameters to manipulate or for finding their correct values). The students actually seem to hesitate (46.-49.) after finding that the two algebraic expressions are the "same" (45.): as a matter of fact they finally resort to the comparison between graphs in order to confirm the algebraic outcomes (50.). Students' hesitation is not surprising: the material milieu is purposefully designed to stimulate both the connection of different registers (the graphical and the algebraic ones), and the recognition of the relationships between specific actions on Casyopée (e.g. piloting the parameters) and Casyopée respective feedback (e.g. corresponding changes of the graph and of the expression of the functions). The $a$ didactical potential of the situation runs as planned. The material milieu is reactive and provides two complementary types of feedback: one on the graphs and the other on the algebraic expressions.

\footnotetext{
${ }^{9}$ For a discussion of how social interactions are taken into account by the TDS see Kidron, Lenfant, Bikner-Ahsbahs, Artigue and Dreyfus (2008).
} 
TSM. The last items of the excerpt reveal the progressive unfolding of the semiotic potential realized through the students' interventions. While in the previous part the students' interventions concerned the role of the parameters and the connections between parameters values and position of the graph in the plane, the last interventions refer to the algebraic expression of the function and consist in establishing connections between the algebraic expression and the graph of the function. All this can provide the ground for the teacher's future interventions oriented towards the explicit re-elaboration of the meanings related to the relationship between algebraic expression and graph of a function.

Excerpt 2: connection between the material milieu and the objective milieu, and knowledge injection from the teacher - elaboration of signs, and the teacher's contribution to the construction of a semiotic chain

After having found the correct values of the parameters, the students are required to explain the method followed (task2): at this point Jus and Luc ask for the teacher (T) to help them.

106. Jus: Sir, for the methods, how can we do?

107. Luc: Ah!

108. Jus: Because we do not have really any method

109. T: So, what were you doing?

110. Luc: But ...it is with ...

111. T: Your method was consisting in doing what, in fact?

112. Jus: Well... we were looking at the graph, for instance we have to move forward so we can act on the parameter in this way ...

113. T: But the way you move forward, did you think of something, more or less consciously?

114. Jus: Bah... yes for example $k$

115. T: You were thinking... to... what kind of geometrical transformations?

116. Jus: Well..., some translations

117. T: Well some translations and the choice...

118. Luc: And to some dilations

TDS. There is a change in the type of situation which shifts from an "action situation" (task 1) to a "formulation situation" (task 2). This type of situation is not so usual for students. Moreover, there is no adequate a-didactical milieu. Having neither adequate feedback nor sufficient knowledge to cope with this task, students call the teacher. That shows the underestimation (in the design) of the difference between the two types of situations and the need for a specific devolution. Indeed, students can't connect by themselves the material milieu and 
the objective milieu. The request of the teacher's help can be seen as a change of didactical contract: within the didactical contract established in the class for this situation, a new contract is initiated by Jus (106.) who gives back to the teacher the responsibility of the formulation of the solving strategy, and consequently of the construction of new knowledge .


teacher asks Jus and Luc to make explicit how they used the artefact for accomplishing the task (109.). The aim is to foster the reconstruction of the context of the task and of the modality of use of the artefact in that context. While describing her method (112.), Jus relates the observation of the graph, and the identification of a need to move the graph ("move forward"), with the need to act upon the parameter ("act on the parameter"). The link between parameter and transformation of the graph is still implicit: it is condensed in the "so" (112).

TDS. Students were asked to explain the methods used. The teacher shifts the discussion (113) from a focus on the method towards a focus on their "more or less consciously" thinking. Then he directly injects knowledge in the objective milieu to allow the students to continue to solve the task 2: "what kind of geometrical transformations?" (115.).

TSM. The use of the term "transformation" feeds the construction of a semiotic chain from the artefact signs "move forward", etc. to the mathematical signs: transformation, translations, etc. (116. and 118.). In fact the term "transformation" is immediately decoded by students as a mathematical term. The students' answer is in tune: they introduce the mathematical term "translation" and later on the term "dilation". Despite the fact that "translation" and "dilation" are mathematical terms, there is the risk that the meaning attached to them is still confined to the actual use of Casyopée.

$\underline{\text { TDS. }}$. These teacher's interventions can be seen as an anticipation of the institutionalisation phase in a formulation situation. The meaning attached by students to the geometrical transformations remain linked to Casyopée, but being in a formulation situation, this is consistent with the TE design.

\subsection{Cross-analysis of the Unisi TE discussion}

The excerpt analysed hereafter is drawn from a classroom discussion held in the fifth session. This is the second classroom discussion (another one was held in the third session). In sessions 2 and 4, the students engaged two optimization problems. The former required to find the maximum value of the area of a rectangle inscribed in given triangle. The latter required to find the minimum value of the sum of the areas of two polygons constructed within a given triangle. The discussion held in session 5 starts from: (a) students' different possible solutions for the optimization problem addressed in session 4; (b) the comparison between these solutions and those given to the optimization problem addressed in session 2; and (c) students' written reports as well.. The objective is not to 
validate students' solutions, or to compare them, but rather to arrive at an explicit, shared, de-contextualised formulation of the mathematical meanings at stake.

\section{Excerpt 1: specification of the motive of the activity, and elaboration of signs emerging from the activities with the artefact - preparation of the objective milieu, and distribution of responsibility}

1. T: What are the issues in the resolution of this second type? I mean, basically, what were you asked to do as homework? I mean what are the main issues when you try to solve this kind of problem, what kind of problem were we looking at... Come on, who wants to start? Come on guys. This is the one that... every problem is a different world right? Because every problem has its own solution. What is the important thing that you need to do? You need to try to understand which generalities there are and then try to apply them to all the possible problems in the future with and without the software because these are also two important aspects and this... the software, guys... did you... because it emphasizes particular important issues. Cor would you like to try to start? Break the ice.

2. Cor: $[\ldots]$ First of all we had to choose the triangle by giving coordinates

[Students recall the steps to represent the geometrical situation within Casyopée DGE]

5. Luc: But you have to choose a mobile point, first [...]

6. T: Does everybody agree? [...] How would you label this first part? $[\ldots]$

7. Students: Setting up

8. T: Luc has just highlighted something [...] do you see anything similar between the two problems?

9. Sam: One has always to take a free point which varies, in this case, the areas considered $[\ldots]$

10. T: Then we have a figure which is...

11. Students: Mobile.

12. T: Mobile, dynamical. Let us pass to the second phase. Andrea, which is the next phase? [...]

13. And: The observation of the figure would let us see... we need to study that figure and observe what the shift of the variable causes...

14. T: Ok, then? Everybody did that, right? 
15. Sil: We computed the area of the triangle and of the parallelogram, we summed them, and by shifting the mobile point we observed how [the sum of the areas] varied [...]

TSM. Collective discussions constitute the core of the semiotic mediation process, aiming at fostering the evolution from personal to mathematical meanings. Through her initial intervention the teacher specifies the motive of the activity. She asks to go back to the task focusing on Casyopée, soliciting students' account on the use of the tool in the solution of the task, in order to make personal signs emerge in relation to the use of the tool. From a semiotic perspective we can interpret the suggestion to refer explicitly to the use of Casyopée as aiming at triggering the production and use of artefact-signs and the unfolding of the semiotic potential. At the same time, the request for generalization can be interpreted as aimed to promote the evolution of personal signs towards mathematical ones, which are, by their very nature, general and de-contextualized.

TDS. According to the point of view of the TDS, the teacher prepares the objective milieu for the collective discussion. She refers to the material milieu with Casyopée, but she wants students to think within an evoked milieu (that is, she wants students to evoke the proper milieu of the activity with Casyopée without having the tool available). It can be interpreted as a double decontextualisation: from the artefact and from the action. The fact that the material milieu is only evoked and cannot be acted upon is expected to foster the student's verbalization. The following exchanges witness the interplay between the material and the evoked milieu and its functioning according to the teacher's expectations. Through this intervention of the teacher, a specific didactical contract is established, which is quite unusual with respect to French habits for two reasons. First of all, it is a collective production contract: that is, the teacher gives the students the whole responsibility of the production and validation of the answers, while her role is to moderate the students' debate (Hersant \& Perrin-Glorian, 2005, p. 132). Secondly, the focus is not on the students' appropriation of an artefact or on its transformation into a personal instrument embedding mathematical knowledge, or on the real achievement of the task. The situation shares some characteristics of a formulation situation, but also shares some characteristics of a situation of institutionalization where new knowledge is elaborated,.

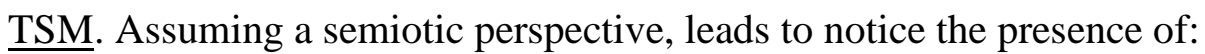

(a) Elements of a collectively constructed semiotic chain, in which a connection is established from artefact signs ("mobile point") to mathematical signs ("variable") and vice versa: "movable point" (5.), "free point" (9.), "variable" (13.), and "movable point" (15.). This semiotic chain shows: (i) students' recognition that geometrical objects can be considered (can be treated, can act) as variables, and (ii) the enrichment of students' meanings of variable to include meanings related to motion. 
(b) Elements of a collectively constructed semiotic chain, in which the meaning of function as a relation of co-variation of two variables emerges: "a free point which varies $[\ldots]$ the areas" (9.), "the shift of the variable causes" (13.), "by shifting the movable point, one observed as [the sum of the areas] varied" (15.).

The teacher actively participates to the construction of the semiotic chains feeding the discussion by introducing specific signs, possibly echoed by students, focalizing the class attention, emphasizing some students' contributions, driving the discussion.

TDS. The teacher questions what has been said so far: "Does everybody agree?" (6.). This is a typical expression for the students. Its main goal is just to break the thread of the students' report without censuring it. This intervention breaks the current didactical contract where the responsibility was given to students and shifts it from a collective production contract to an adhesion contract (PerrinGlorian \& Hersant, 2003, p. 245), according to which students are expected only to express their disagreement, while their silence is interpreted as an implicit agreement and announce the closure of the topic. Such interruption allows the teacher to change the focus and start preparing the milieu in order to make emerge the fact that the two problems share similarities: "How would you label this first part?" (6.) and "do you see anything similar between the two problems?"(8.). The responsibility appears clearly to be on the side of the teacher as it is confirmed by her intervention which closes the episode "Mobile, dynamical. Let us pass to the second phase" (12).

TSM. The two teacher's interventions (6. and 8.) are crucial for the development of the semiotic mediation process: they correspond to important semiotic actions. The former contains a request for naming ("How would you label this first part?"), which could foster synthesis and generalization. The latter ("Luc has just highlighted something") aims at focalizing the attention of the class towards the sign "mobile point" previously introduced by Luc (5.) and re-launch the motive of the activity (and "do you see anything similar between the two problems?" (8.). The sign "mobile" is clearly related to the task and the use of Casyopée, but, at the same time, it may be related to the mathematical knowledge at stake: the notion of variable. That is why the teacher decides to emphasize Luc's contribution. Afterwards, Sam echoes Luc's intervention introducing a new sign and contributing to the generation of the semiotic chain (9.). Sam's contribution ends with the reference to variable areas.

TDS. In the following exchange the teacher asks students to complete her sentence with a single word (10.), Taking a TDS perspective this could be 
interpreted as a so called Topaze effect ${ }^{10}$ (Brousseau 1997). However, the teacher doesn't seem to wait for a precise answer. So, following Hersant and PerrinGlorian (2005), we speak of regulation of the didactical contract and management of ruptures in it: with questions which guide the students' reflection, the teacher reduces the uncertainty of students without, however, completely eliminating it.

TSM. The intervention of Sam (9.) could have prematurely moved the discussion towards the consideration of algebraic or numerical aspects of the problem, without giving time to elaborate on the notion of variable and variation in the geometric setting. Thus the Topaze effect finds an interpretation according to a general design of the teacher: the intervention of the teacher is a semiotic game through which she purposefully introduces the term "figure" (10.) in order to contrast the risk of dispersing the arguments. The introduction of the term "figure" does not close the discussion; it only has the effect of keeping students' attention still on the geometrical objects. As a matter of fact, the use of the term "figure" will be echoed by And (13.), who makes explicit also the co-variation between the geometrical objects in focus.

\section{Excerpt 2: elaboration of signs from a specific artefact-sign - connecting the material and the objective milieu}

16. T: Yes, I wait; let's say, in the second phase, which specific commands of the software are you using? Silvia, try to remember a bit by heart or looking at your notes. I construct the sum of the requested areas. In the other problem you had the area of the...

17. Students: Rectangle.

18. T: Good. Anyway, what are you using of the software?

19. A student: A part ... what is the part with the button... I don't remember.

20. T: Uh, a specific button, come on what is it called?

21. Students: OM squared... OM square root... ${ }^{11}$

22. T: Can we find this button? this way of working that lets us do this first part?

23. Students: Geometric calculation.(English term used by students)

24. Others: Dynamic geometry.(English term used by students)

10 The Topaze effect is the phenomenon which occurs when the answer of a question is so strongly suggested by the context, that the students do not need to produce an answer themselves; they know what to answer by virtue of implicit contract. It refers to a theater play of Marcel Pagnol (1895-1974).

${ }^{11}$ There is the reference to the icon which identifies the button for launching the Geometric calculation environment (Figures 2 and 3). 
25. Dan: No, geometric calculation... dynamic geometry - what is it called - it's the one where there is the figure.

26. T: So if we want to call it something in Italian we could give it a name... Shall we write geometric calculation like she says? Do you all agree?

27. Students: In Italian.

28. Another student: I don't understand why in English...

29. T: Exactly. So, let's do this since we do not have the software in front of us anyhow. So let's find an Italian word that you think...

30. A third student: Calcolatore geometrico (English:. Geometric calculator).

31. T: To remember, to all agree on. Calcolatrice (English:. Calculator)? Is calcolatrice good?

32. Val: But isn't it linked to...

33. Dan: But it has to do with the drawing... calcolatrice, Val is right... it is called geometric calculation... because...

34. T: Calcolatrice, don't you like calcolatrice? Why don't you like calcolatrice?

35. A fourth student: It is not a calcolatrice.

36. Sam: You have to consider the geometric functions, not the calculation functions

37. Sil: if it were a calcolatrice, it would execute a calculation, and then when you move the point, nothing would change. Instead, dragging the mobile point A I mean they update the result anyway.

38. T: So shall we call it calcolo (English: Calculation)? Will calcolo do?

39. Students: Geometrico.

40. T: Calcolo geometrico. So, let's say something. What is it that allowed us to construct this calcolo geometrico? When you don't have Casyopée, what similar thing did you have to do in this phase?

TDS. The first previous excerpt showed several interventions of the teacher $(2 ., 8$. and 12.) meant to prepare the objective milieu of the discussion: from the recognition of the similarities between the two problems to the de-contextualised description of the solving strategies. The students' answers, instead, still had a strong reference to the material milieu (15.). This excerpt opens with the teacher deliberately referring to the material milieu (16., 18. and 20.). The teacher focuses on a specific command of Casyopée and does not refer to any mathematical notion or procedure involved in the solution of the problems. The material milieu doesn't embed enough mathematical knowledge and it seems difficult for the 
students to connect the material milieu and the objective milieu: the students' answer remains at the material level and the teachers must help students to focus on the generic aspects of the two problems.

TSM. The semiotic analysis highlights the appearance of new artefact-signs "OM square root" (21.), "Geometric calculation" (23.), "Dynamic geometry" (24). Through the elaboration of such signs the teacher aims at fostering a generalization towards the idea of modelling. The teacher's request of translating (26.) re-launches the problem of interpreting the use of the command and fosters the emergence of the students' personal meanings as emerge through the production of personal signs. The teacher's insistence on the term "calcolatrice" (31. and 34.) can be interpreted as an attempt to push students to recognize the possibility of establishing algebraic relationships between the geometrical objects involved in the problem.

TDS. The teacher's attempt to force the students to accept the term "calcolatrice" could be seen as a Topaze effect. It seems to be a rupture in the specific contract of the discussion. As it is often the case, it may happen that although the development of the meanings is mature for moving to the mathematical context, a gap has to be overcome. Students cannot know in advance what precisely the link with mathematics is, and to some extent they are invited to guess what the teacher wants them to say.

TSM. The teacher's proposal is rejected (32., 35., 36. and 39.) in favour of "Calcolatore geometrico" (30.), which values the possibility of expressing the geometrical relationships before the numerical ones. The students want to keep the geometrical reference: they defend their preference trying to make clear exactly those meanings evoked by the geometrical reference and which would be lost if such reference was not kept.

TDS. The students' resistance to the teacher's pressure shows that for the students the reference to the material milieu is still indispensable and cannot be abandoned. The teacher tries to gather as many students as possible around what is constructed in the discussion. She tries to obtain a consensus. From a TDS perspective, this action may compensate the low a-didactical character of the Casyopée task which does not allow the students to connect material actions and mathematical knowledge by themselves. The teacher keeps the whole responsibility of the discussion by ending the episode and beginning another one What is it that allowed us to construct this calcolo geometrico? (40.).

TSM. The students' resistance also shows that we are not assisting to a Topaze effect. Students do not have the intention to please the teacher per se. On the contrary, being concerned with maintaining the geometrical meaning coming from the use of the artefact, they defend their proposal against the teacher's. Finally, the teacher accepts the students' objections and their proposal and orients the discussion towards a de-contextualization from the artefact, and consequently 
towards the possible emergence of the corresponding mathematical meanings in the modelling process.

\section{Synthesis}

In this section we synthesize the main connections between TSM and TDS emerging from the cross-analysis. In particular we focus on: the students' use of the artefact for accomplishing a task, and the social interaction between teacher and students following the activity with the artefact.

\subsection{The use of an artefact for accomplishing a task}

The idea of task is central in both the theoretical approaches: they share the view that tasks can be purposefully designed to lead students' learning processes. However the way the learning is conceptualized is different, and reveals the different psychological roots of the two approaches. In fact, according to the TDS, learning is mainly a process of adaptation to a milieu organised so as to cause disequilibrium allowing the construction of new knowledge, while according to the TSM learning is a process of construction of meanings intentionally guided by an expert.

\section{"Functioning of the a-didactical situation" and "Unfolding of the semiotic potential"}

Assuming a TDS perspective leads one to focus mainly on students' actions and the feedback from the milieu. The analysis of how the milieu is organized, and of the different kinds of feedback it provides, is at the core of the TDS analysis (see for instance the analysis of the excerpt 1, section 4.1). This analysis is meant to investigate whether the a-didactical potential of the situation is realized as expected, that is whether the students establish the expected connections between the material and the objective milieu, these connections being facilitated by interactions between students. The focus is on the new knowledge emerging from the individual's interpretation of the interplay between actions, the feedback from the milieu and students' interactions, with as a minimal as possible intervention of the teacher.

On the same excerpt the TSM analysis dwells on the students' semiotic activities related to the accomplishment of the task through the use of the artefact. The analysis focuses on the students' production and use of signs, and specifically of artefact-signs (e.g. "descendre", "parameter"). The analysis reveals how semiotic activities lead students' meaning-making in ways consistent with both the artefact functionalities and the envisaged mathematical meanings, or in other words the unfolding of the semiotic potential of the artefact. The feedback of the artefact is considered with respect to its potential to trigger the production of signs and to provide a common reference for its use. 


\section{"Knowledge injection from the teacher" and "The teacher's contribution to the construction of a semiotic chain"}

From the TDS perspective, the didactical contract foresees students' autonomy in the accomplishment of the task, any mathematical intervention of the teacher during the activity with the artefact is conceived as a violation of the didactical contract. However the students ask for the teacher's help and according to our interpretation (section 4.1, excerpt 2) this occurs because of the lack of adequate feedback from the milieu and of students' knowledge for coping with the formulation task. This marks a change of didactical contract, and the consequent shift of responsibility from the students to the teacher. The teacher's intervention has the effect to inject new knowledge into the situation to allow the students to progress through the accomplishment of the task and to connect the material to the objective milieu. In the TDS perspective, formulation phases are at the interface between action phases and validation/institutionalisation phases. There is a need for specific devolution for this kind of phase and the TSM approach can suggest specific intervention in the form of semiotic games to better manage such phases in the sense of a collective production contract.

As a matter of fact, taking a semiotic perspective, the analysis of the teacher's intervention shows how her utterances contributes to reconstructing the context of the task and of the modality of use of the artefact in order to trigger the students' production and elaboration of signs concerning their use of the artefact. At the same time, the teacher helps students to connect personal signs with mathematical signs, through feeding the construction of a specific semiotic chain. The connection between personal and mathematical signs cannot be achieved by students alone; the intervention of the teacher is to be considered a necessity to foster such connection.

\subsection{Social interactions between teacher and students}

A crucial didactical issue concerns the relationship between individuals' knowledge, easily recognizable by an expert in students' actions and speeches, and the mathematical knowledge that is the objective of the didactical intervention. In other words, there is the problem of making students aware of the developed knowledge and its link with the target knowledge, which needs to be made explicit and formulated in a general, de-contextualised and de-personalized manner.

\section{"Specification of the motive of the activity" and "Preparation of the milieu"}

According to the TSM perspective, the crucial point is how to relate personal signs with mathematical signs. The link between the accomplishment of the task and the mathematics has to be built on the texture of personal signs emerging from the task. The evolution of students' personal signs can be realized through a mathematical discussion orchestrated by the teacher. However, in the TSM sense, any mathematical discussion would not be possible if students do not share its 
main motive. For this very reason, the teacher intervenes during the discussion to specify and re-launch the motive of the activity (see items 1 and 8, excerpt 1 , section 4.2). These same interventions can be interpreted from a TDS perspective as aimed at preparing the objective milieu and establishing and reshaping the specific didactical contract of the discussion. In fact, the motive expressed by the teacher makes sense with respect to a macro didactical contract which has to be settled in the class in order to make a mathematical discussion occur (Falcade, 2006). Such a didactical contract concerns how and why using the artefact to solve the task can be interpreted mathematically and vice versa how and why mathematics can be interpreted by artefact tools and their use. The teacher's interventions aimed at developing the semiotic process of texture, mentioned above, can be interpreted as consistent with such a didactical contract. According to the TDS, the analysis of teacher's and students' interventions reveals the complex structure of the milieu of the collective discussion, where it is possible to recognize interweaving references to a material, an evoked and an objective milieu.

\section{"Elaboration of signs emerging from the activities with the artefact" and "Distribution of responsibility"}

A semiotic analysis of teacher's intervention shows a process of texture consisting in the elaboration of signs, which is based on the previous activities with the artefact and on the specific signs that emerged from those activities (such as specific artefact-signs). The role of the teacher is crucial in fostering the evolution of students' personal signs; hence the analysis also focuses on how the teacher feeds this elaboration. The elaboration of signs is revealed through the construction of semiotic chains to which the teacher actively participates (excerpts 1 and 2, section 4.2).

The TDS perspective highlights the existing relationships between elaboration of signs and interplay of the material, objective and evoked milieu. This interplay is often accompanied by a reshaping of the didactical contract. The dynamic of the distribution of responsibility, in particular, may mark the shifts between the collective production contract and the adhesion contract (excerpts 1 and 2, section 4.2). However, within the macro didactical contract of the classroom discussion, one observes a continuous transfer of responsibility between the teacher and the students during the discussion, transfer that is often managed by the teacher through specific intervention in the form of semiotic plots.

\section{Conclusions}

The synthesis above presented the multiple connections between TDS and TSM, brought to light through the methodology of cross-analysis (which, as already stressed, was developed and refined in use during the project itself). The crossanalysis highlights how specific theoretical elements elaborated within the TSM and within the TDS can help describe and clarify various aspects of the 
mathematics teaching and learning process. Different tools provide different lenses contributing to a reciprocal enrichment of the analysis of specific didactical phenomena. For instance, on the one hand, a TSM perspective sheds new light on what happens in a situation of formulation, in which students are asked to communicate their solution. The TSM provides specific tools for the analysis of collective discourse describing the development of students' knowledge and their awareness about it. From this perspective, it may happen that the teacher's interventions can be re-conceptualised and may no longer seen as a violation of a requested didactic contract, as far as they can be interpreted according to the motive of a more general activity. On the other hand, assuming a TDS perspective helps clarify the development of the semiotic processes that occur during the classroom discussion, describing how such processes are kept alive through a continuous re-distribution of responsibility, and how the evolution of signs is driven through the evolution of the evoked milieu.

The claimed synergy between the TDS and the TSM perspectives consists exactly in the shown connection between the theoretical analytical tools that provides a richer interpretation of what happened in the classrooms, and in the highlighted complementarities between the two theoretical perspectives that allow questioning, clarifying and complementing each other, thus resulting in a reciprocal enrichment.

Questioning. For instance, a TSM regard on the students' interactions when they work with Casyopée reveals the risk that the knowledge (or the meanings) developed by students is confined to the actual use of Casyopée, and that the connections between the material and the objective milieu (between personal and mathematical signs) may be weaker than expected and desired. Or, conversely, a TDS regard raises the issue of the need of a specific didactical contract for the collective discussions and reveals the risk of possible Topaze effects.

Clarifying. As a reaction to this reciprocal questioning, the authors engaged in a process of re-elaborating, deepening, and clarifying some elements of their analysis; and this process lead to clarify theoretical issues and constructs taking into account each others' perspective. For instance, the TDS approach permits to clarify the process of task design and the analysis of the semiotic potential related to it, through an analysis of the milieu(x) involved in the different tasks. It also permits to clarify the analysis of collective discussions: the distinction between the material, the evoked and the objective milieu allows a clearer description of the development of the discourse and of the specific motives of the teacher's interventions. Similarly, the semiotic perspective introduced by the TSM permits to clarify the development of the didactic contract according to the shifts of responsibilities between the teacher and the students and the motives of their interventions, either explicitly expressed or implicitly reconstructed. This is case of the pseudo Topaze effect discussed above. The interpretation of the teacher intervention makes sense not in terms of triggering an immediate, automatic response, rather in terms of a general motive: the intervention of the teacher is a 
semiotic game through which she purposefully intends to focus and keep the students' attention on the geometrical objects.

Complementing. The above process led to recognize several elements of one perspective which are very relevant for the other, too. For instance, the notions of "re-shaping of the didactical contract" and of "distribution of responsibility", though not in focus in a TSM perspective, are very relevant when one considers the teacher's and students' semiotic actions in the context of a collective discussion, and their goals with respect to the shared motive of the development of mathematical meanings. Conversely, though TDS does not assume an explicit semiotic perspective, nevertheless one can regard the teacher's interventions in a formulation phase as aiming at triggering the students' production of signs concerning their use of the artefact. That helps describe in a more articulated way how the passage from the action to the institutionalisation phase can be managed: a semiotic analysis allows a description of the teacher's intervention that overcomes its interpretation merely as a break of the didactical contract.

These processes - questioning, clarifying and complementing - constitute the core of what we called a reciprocal enrichment of the two theoretical perspectives. However, we want to acknowledge and stress that, as one of the reviewers of this article remarked, the highlighted synergy between the two theoretical perspectives is not (and could not be) the effect of the cross-analysis methodology alone, but it results from a positive highly collaborative attitude of the researchers involved in the project.

\section{Acknowledgements}

Research funded by the European Community under the VI Framework Programme, IST-4-26751STP "ReMath: Representing Mathematics with Digital Media”, http://www.remath.cti.gr.

\section{References}

Artigue, M. (2002). Learning Mathematics in a CAS Environment: The Genesis of a Reflection about Instrumentation and the Dialectics between Technical and Conceptual Work. International Journal for Computers in Mathematical Learning, 7(3), 245-274.

Artigue, M. (2008). Digital technologies: a window on theoretical issues in mathematics education. European Research in Mathematics Education V. Proceeding of CERME5 (pp. 68-82). Larnaca, Chyprus.

Artigue, M. (Ed.) (2009). Integrated Theoretical Framework (Version C). Deliverable 18. Retrieved from ReMath Project website: http://remath.cti.gr

Artigue, M., Bosch, M., \& Gascón, J. (2011). Research praxeologies and networking theories. Proceedings of CERME 7 ( pp. 2381-90). Rzeszów, Poland: University of Rzeszów.

Artigue, M., Cerulli, M., Haspekiam, M., \& Maracci, M. (2009). Connecting and Integrating Theoretical Frames: The TELMA Contribution. International Journal of Computers for Mathematical Learning, 14 (3), 217-240. 
Arzarello, F. (2006). Semiosis as a multimodal process. Relime 9(1), 267-299.

Bartolini Bussi, M.G., \& Mariotti, M.A. (2008). Semiotic Mediation in the Mathematics Classroom: Artifacts and Signs after a Vygotskian Perspective. In L.D. English (Ed.), Handbook of International Research in Mathematics Education (pp. 750-787). Mahwah, NJ: LEA.

Bikner-Ahsbahs, A. (2010). Networking of theories: why and how? Proceedings of CERME 6, (pp. 6-15). Lyon, France: INRP.

Borba, M.C., \& Villarreal, M.E. (2005). Humans-with-media and the Reorganization of Mathematical Thinking: Information and Communication Technologies, Modeling, Visualization and Experimentation. New York: Springer.

Bottino, R.M., Artigue, M., \& Noss, R. (2009). Building European Collaboration in TechnologyEnhanced Learning in Mathematics. In N. Balacheff, S. Ludvigsen, T. de Jong, A. Lazonder, \& S. Barnes (Eds.) Technology enhanced learning: principals and products (pp.73-87). Springer Science.

Brousseau, G. (1997). Theory of Didactical Situations in Mathematics. Kluwer Academic Publishers.

Cerulli, M., Pedemonte, B., \& Robotti, E. (2006). An integrated perspective to approach technology in mathematics education. European Research in Mathematics Education IV. Proceeding of CERME4 (1389-1399). Sant Feliu de Guíxols, Spain.

Cerulli, M., Trgalova, J., Maracci, M., Psycharis, G., \& Georget J.-P. (2008). Comparing theoretical frameworks enacted in experimental research: TELMA experience. ZDM, Comparing, Combining, Coordinating - Networking Strategies for Connecting Theoretical Approaches, 40(2), 201-213.

Chevallard, Y. (1999). L'analyse des pratiques enseignantes en théorie anthropologique du didactique. Recherches en Didactique des Mathématiques, 19(2), 73-112.

Duval, R. (1995). Sémiosis et pensée humaine: registres sémiotiques et apprentissages intellectuels. Berne: Peter Lang.

Falcade, R. (2006). Théorie des Situations, médiation sémiotique et discussions collective, dans des séquences d'enseignement avec Cabri-Géomètre pour la construction des notions de fonction et graphe de fonction. Grenoble: Université J. Fourier, unpublished doctoral dissertation.

Hasan, R. (2002). Semiotic mediation, language and society: three exotripic theories - Vygotsky, Halliday and Bernstein. In J. Webster (Ed.) Language, Society and Consciousness: The Collected Works of Ruqaiya Hasan, Vol 1. London: Equinox.

Hersant, M., \& Perrin-Glorian, M.J. (2005). Characterization of an ordinary teaching practice with the help of the theory of didactic situations. Educational Studies in Mathematics, 59(1), 113-151.

Hoyles, C., \& Lagrange, J.-B. (Eds.) (2010). Mathematics Education and Technology-Rethinking the Terrain: The 17th ICMI Study. New York: Springer.

Kidron, I., Bikner-Ahsbahs, A., Monaghan, J., Radford L., \& Sensevy, G. (2011) Introduction to the papers of WG 16: Different theoretical perspectives and approaches in research in mathematics education. Proceedings of CERME 7 (pp. 2376-80). Rzeszów, Poland: University of Rzeszów.

Kidron, I., Lenfant, A., Bikner-Ahsbahs, A., Artigue, M., \& Dreyfus, T. (2008). Toward networking three theoretical approaches: the case of social interactions. Zentralblatt für Didaktik der Mathematik - The International Journal on Mathematics Education, 40(2), 247-264. 
Kozulin, A. (2003). Psychological tools and mediated learning. In A. Kozulin, B. Gindis, V.S. Ageyev, \& S.M. Miller (Eds.), Vygotsky's Educational Theory in Cultural Context (pp. 15 -38). Cambridge: Cambridge University Press.

Kynigos, C., \& Psycharis, G. (2009). Investigating the role of context in experimental research involving the use of digital media for the learning of mathematics: boundary objects as vehicles for integration. International Journal of Computers for Mathematical Learning, 14(3), 265-298.

Lagrange, J.-B. (2010). Teaching and learning about functions at upper secondary level: designing and experimenting the software environment Casyopée. International Journal of Mathematical Education in Science and Technology, 41(2), 243-255.

Maracci, M., Cazes, C., Vandebrouk, F., \& Mariotti, M.A. (2009). Casyopée in the classroom: two different theory-driven pedagogical approaches. Proceedings of CERME6 (pp. 1399-1408). Lyon, France: INRP.

Mariotti, M.A. (2009). Artifacts and signs after a Vygotskian perspective: the role of the teacher. ZDM, Transforming Mathematics Education through the Use of Dynamic Mathematics Technologies, 41(4), 427-440.

Mariotti, M.A., \& Maracci, M. (Eds.) (2008). Design-Based Research: Process And Results. Deliverable 13. Retrieved from ReMath Project website: http://remath.cti.gr

Mariotti, M.A., \& Maracci, M. (2010). Un artefact comme outil de médiation sémiotique : une ressource pour le professeur. In G. Gueudet \& L. Trouche (Eds.) Ressources vives. Le travail documentaire des professeurs en mathématiques (pp. 91-107). Rennes: Presses Universitaires de Rennes et INRP.

Margolinas, C. (Ed.) (1995). Les débats de didactique des mathématiques. Grenoble: La Pensée sauvage éditions.

Mason, J. (2010). Discerning in and between theories in mathematics education. Proceedings of CERME 7 ( pp. 2483-92). Rzeszów, Poland: University of Rzeszów.

Meira, L. (1995). Mediation by Tools in the Mathematics Classroom. In L. Meira \& D. Carraher (Eds.), Proc. of the 19th Conf. of the Int. Group for the Psychology of Mathematics Education (Vol I, pp. 102-111). Recife, Brazil: PME.

Monaghan, J. (2010). Theoretical genesis of an informal meta-theory to develop a way of talking about mathematics and science education and to connect European and North American literature. Proceedings of CERME 7 (pp. 2493-502). Rzeszów, Poland: University of Rzeszów.

Noss, R., \& Hoyles, C. (1996), Windows on Mathematical Meanings. Dordrecht: Kluwer Academic Press.

Perrin-Glorian, M.J., \& Hersant, M. (2003). Milieu et contrat didactique, outils pour l'analyse d'une séquence ordinaire. Recherches en didactiques des mathématiques, 23(2), 217-276.

Prediger, S., Bikner-Ahsbahs, A., \& Arzarello, F. (2008). Networking strategies and methods for connecting theoretical approaches - First steps towards a conceptual framework. ZDM - The International Journal on Mathematics Education, 40(2), 165-178.

Radford, L. (2003). Gestures, speech, and the sprouting of signs: A semiotic-cultural approach to students' types of generalization. Mathematical Thinking and Learning, 5(1), 37-70.

Radford, L. (2008). Connecting theories in mathematics education: Challenges and possibilities. ZDM - The International Journal on Mathematics Education, 40(2), 317-327. 
Robert, A. (1998). Outils d'analyse des contenus mathématiques enseignés au lycée et à l'université. Recherches en Didactique des Mathématiques, 18(2), 139-190.

Vygotsky, L.S. (1978). Mind in Society. The Development of Higher Psychological Processes. Harvard University Press. 